\title{
Orthodontic Contribution to Orthognathic Surgery Cases
}

\author{
Nikolaos Topouzelis \\ Aristotle University of Thessaloniki, Dental School
}

Greece

\section{Introduction}

Skeletal malocclusion (dysgnathia) is defined as the congenital or acquired abnormal position or morphology of one or both jaws. There might be symmetry or asymmetry with disruption of the maxillomandibular relationship or the relationship of the jaws to the skull base combined with malocclusion or joint disruption. The main treatment objectives for serious skeletal malocclusions are aesthetic, functional and psychological rehabilitation. For this kind of cases these goals may be achieved. The orthodontist can move teeth and alveoli but this has no substantial impact on the adult basal jaw bone. The main orthodontist's task is teeth alignment. The oral \& maxilofacial surgeon is responsible for the surgical correction of jaws and their associated structures. Generally speaking, the diagnosis and treatment plan of orthognathic cases require a systematic team approach. Although team member composition may differ depending on conditions at any given time, an ideal team should include an orthodontist, a maxillofacial surgeon, a phychiatrist or a clinical phychologist, a prosthetologist and a specialised dental technician. Orthognathic surgery involves risks and this is why we need to proceed with it only after careful planning. It is particularly important to understand the patient's view; this establishes trust and communication and helps achieve high quality results.

The management protocol for dentofacial abnormalities, treated through the cooperation of orthodontics and orthognathic surgery involves taking detailed medical and dental history of the patient, clinical examination, casts analysis, photographs, radiographs analysis (leading to diagnosis and treatment plan), presurgical orthodontics, actual surgery and postsurgical orthodontics.

\section{Medical history}

Taking a comprehensive medical history is of the utmost importance. Most orthognathic patients are young individuals and their health normally allows then to undergo general anaesthesia and extensive surgery. However, there are specific disorders, such as blood diseases (coagulation disorders), hormonal disorders, heart diseases, allergies, rheumatic diseases, respiratory diseases (sleep apneoa), which require special treatment (Harris \& Hunt, 2008).

Very serious facial disproportions might be associated with systemic diseases, such as acromegaly (Class III cases) or chronic juvenile arthrities and muscular dystrophy (Class II 
cases with open bite). Such medical problems complicate orthognathic treatment and may lead to a generally unstable result if not sufficiently controlled. Furthermore, patients' psychological assessment is essential so as to ensure that their expectations are realistic. Besides, the case of dysmorphobia should be examined, because such patients are totally unsuitable for orthognathic treatment, as they are bound to be disappointed by the result (Winchester \& Young, 2007).

\section{Dental history}

When taking the patient's dental history, existing teeth should be recorded and any caries or periodontal problems identified and treated before orthodontic treatment and orthognathic surgery, in coooperation with specialised dentists. However, there might be problems such as missing teeth which would be better treated after orthognathic surgery. Orthodontic intra-oral examination must include: a) assessment of static and functional occlusion and dental base relationships in the three spatial dimensions. It is important to check and record if there are extreme lateral or protrusive mandibular movements along the mandible elevation path, in cases of anterior or posterior cross-bite and in cases of disruption of the relationship between the upper and lower midline or the relationship between the upper and lower midlline the midline of the face; $b$ ) the presence of tooth spacing or crowding in relation to possible tooth size or morphology disorders; c) the presence of tooth displacement or rotation; d) the presence of anterior teeth inclination, since upper incisors become apparent when they are labially inclined, while lower incisors become apparent in patients with Class III skeletal dyscrepancy when these teeth are lingually inclined; e) checking incisal overbite and overjet. In cases of open bite, it should be checked whether there is a step at the occlusal plane in the upper arch and the anterior teeth are positioned higher than the lower ones; f) occlusal plane disorders, which are checked in the anteroposterior and vertical dimensions using the curve of Spee and in the transverse dimension using the curve of Wilson, which assesses the buccal-lingual position of the occlusal surface of posterior upper and lower teeth; g) the morphology of the dental arches and the palate. In cleft cases, a careful analysis of their type and extension is necessary as well as an examination of bone deficits that require grafts (Harris \& Hunt, 2008); h) tongue assessment. A sizeable tongue (macroglossia) may lead to dental and skeletal problems and undermine the stability of the outcome of the orthodontic and orthognathic treatment; it may also cause problems with mastication, speech and breathing; i) examination of tonsil size, since their excessive size may cause respiratory problems; j) recording problems related to masticatory muscles and the temporomandibular joint, so that if related problems appear after treatment, there will be no confusion as to whether they preexisted or not; if possible, such problems should be dealt with before treatment starts. It is important to advise patients to ensure they fully comprehend that orthognathic surgery takes place so as to correct dento-mandibular disorders and its impact on a preexisting temporomandibular dysfunction is unpredictable; in fact the problem may be exacerbated postoperatively (Onizawa et al., 1995).

\section{Clinical examination of the face}

Clinical examination in regard to facial aesthetics and symmetry is more successful when the patient is sitting comfortably, with the horizontal Frankfurt plane parallel to the ground or in a normal position, with the dental arches in central occlusion and the lips totally 
relaxed. The aim of the clinical examination, in combination with cephalometric radiography and photographs is to recognise whether the maxilla, the mandible or both jaws are pathological and to note other important facial features.

\subsection{Frontal clinical examination}

The frontal facial view is what the patient sees in the mirror and it is also what is usually seen by other people in personal interaction. This is why this view is of particular significance. Numerous major facial parameters can be assessed in frontal view in regard to both the vertical and the transverse dimension. Maximum facial width should be assessed through the inter-zygomatic width. The ratio of facial height to width should be 1.3:1 for women and 1.35:1 for men (Fig. 1). Another quite significant measurement is the bigonial width, which should be around 30\% shorter than the bizygomatic width (Fig. 1). However, according to current beauty standards, faces where the bigonial width is longer than normal are preferred (Winchester \& Young, 2007). The conventional way to assess the vertical dimension of the face is to ensure that there are three equal vertical parts (Fig. 1). The upper part is between the hairline and the eyebrows, the middle part between the eyebrows and the base of the nose and the lower part from the base of the nose to the gnathion. It is important to examine if the vertical height of the three parts is excessive or deficient, in particular regarding the middle third that entails the maxilla and the lower third that entails the mandible (Sarver et al., 2003). In the lower facial third, the ratio of the upper lip height to the lower lip and chin height should be 1:2 (Fig. 1). A pronounced labiomental fold may indicate a reduced anterior facial height, while a shallow fold an increased height.

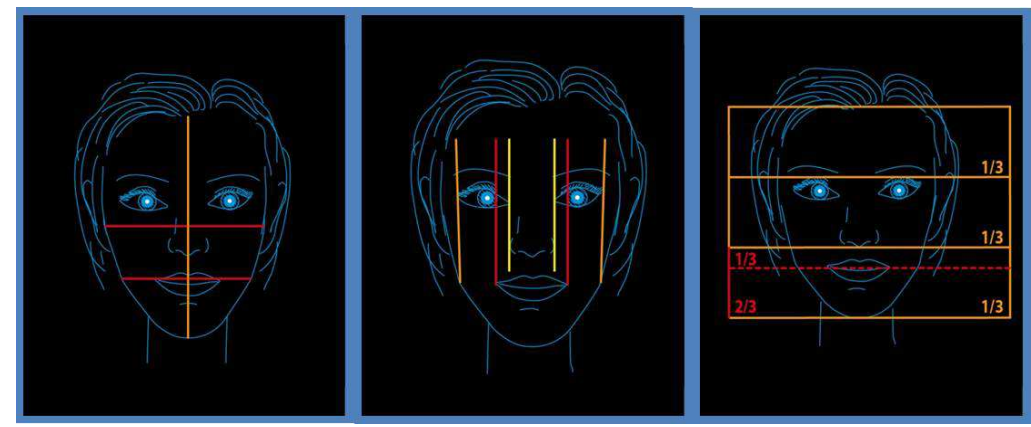

Fig. 1. Facial proportions

When assessing the transverse dimension of the face, it is important to initially note any asymmetry of the middle or lower third of the face. When the upper or lower dental midlines of a patient do not coincide or do not agree with the skeletal midlines (Fig. 9) differential diagnosis is essential in order to follow the right treatment.

The nose is a central structure of the face and plays a particularly important role during clinical examination. Traditionally, among Caucasians, it was acceptable that the alar base width as measured from the lateral aspects of the alar cartilages of the nose, should be more or less equal to the inter-canthal distance, as measured between the medial canthi of the eyes (Fig. 1). This assessment is important when maxillary impaction is planned (Harris \& Hunt, 2008). The width of the mouth should be more or less equal to the distance between the medial borders of the iris (Fig. 1). Similarly, the width of the mandible at the level of the 
gonion should be more or less equal to the distance between the lateral canthi of the eyes (Sarver et al., 2003).

Dentolabial relationships play an important role in facial aesthetics and they should be assessed at a resting position as well as in function while the patient is smiling. The visible part of the teeth and gingivae under the upper lip is important when making a decision concerning maxillary depression or lower maxillary repositioning. At rest, $2-3 \mathrm{~mm}$ of the incisors should be visible. Higher figures, up to $5 \mathrm{~mm}$, have also been proposed (Arnett \& Bermann, 1993a, 1993b) following the rationale that more exposure of the teeth is acceptable among women than among men. When laughing, the whole of the central incisor up to the level of marginal gingivae should be visible or even including 1-2 $\mathrm{mm}$ of the attached gingivae. More extensive exposure of the attached gums is more acceptable among women than among men. (Guariglia \& Ronchi, 2005).

\subsection{Profile clinical examination}

When examining the face from its side view, what is first reviewed are, again, the previously referred vertical proportions (Fig. 2) and any balance and harmony problems in the sagittal dimension.
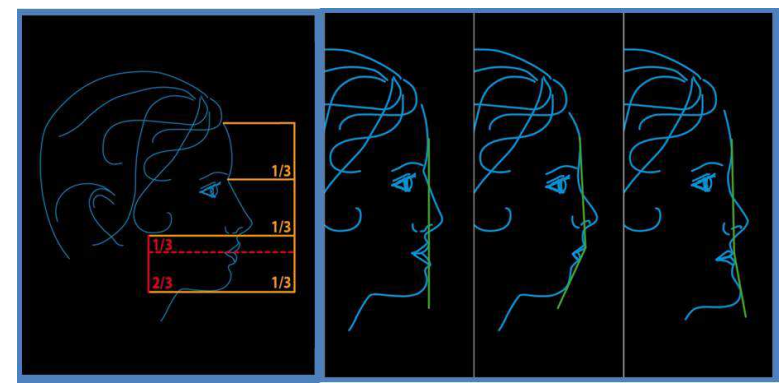

Fig. 2. Vertical proportions and reference lines for facial profile assessment

The nose and its features are also examined because nasal appearance may often undergo related and anatomical alterations in many osteotomies. So, in a Le Fort I osteotomy, maxillary impaction will tend to elevate the tip of the nose and restrict the nasal hump. What should also be assessed is the nasolabial angle; higher values tend to be more acceptable among women, while lower values among men. An acute nasolabial angle may be associated with maxillary hypoplasia and, therefore, may be improved with surgical maxillary protrusion. Controlling maxillary and mandibular protrusion or retrusion is assessed with two vertical lines. The first line goes through the most prominent part of the forehead (Fig. 2) and the second line goes through the soft tissue nasion. In a harmonious face, the end of the lips should touch the first line while maxillary soft tissues should be about $2-3 \mathrm{~mm}$ anterior to the second line and the chin should be $2 \mathrm{~mm}$ posterior to the second line (Winchester \& Young, 2007).

In cases of sagittal disorder of the maxillomandibular relation, differential clinical aetiology diagnosis may become apparent in Class III cases, by filling the upper lip with soft wax or cotton (Fig. 3) until the relationship between the lips and the facial profile approximates what is considered normal. Similarly, surgical correction of a retruded mandible may be represented by asking the patient to slide the mandible forward. 


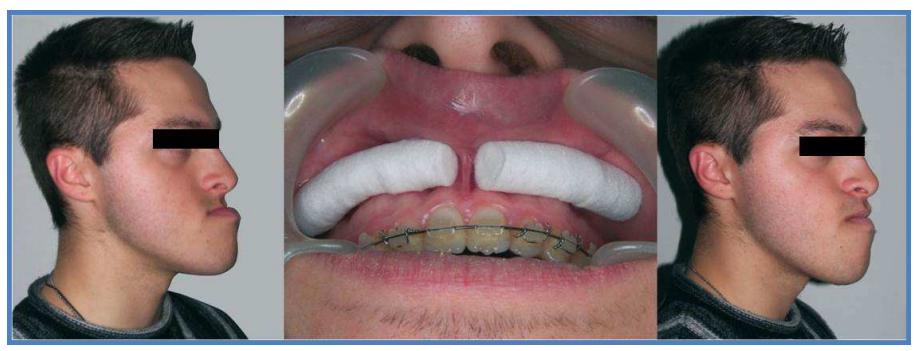

Fig. 3. Change in the facial profile after filling the upper lip with cotton

The submental region should be examined to check for the presence of excessive fat or a double-chin appearance, which is often associated with a short neck. Sometimes, mandibular set back may enhance this subcutaneous tissue deposit. This may be a contraindication for mandibular set back or may make liposuction or plastic surgery necessary. However, among young patients, the submental region is usually spontaneously contoured after the operation.

\section{Laboratory examinations}

\subsection{Casts}

Casts should represent all the teeth that are present, the alveolar processes, the frenulums and the grooves (gingivolabial, gingivo-buccal, gingivolingual). The bases of the casts are trimmed in the intercuspal or central occlusion position, with the help of the corresponding bite records. The casts provide the best data for the assessment of dental problems and static occlusion. Initially they are examined separately in regard to arch shape (parabolic, triangular, square), rotations, deviations and ectopic and infraoccluded teeth. Crowding or spacing is evaluated through the correlation of dental width and the alveolar bone available. The symmetry between the left and right half in the upper and lower dental arches in all three dimensions is assessed, since there might be asymmetries at the vertical level that concern teeth, groups of teeth or the whole of the dental arch, causing an inclination to the transverse occlusal plane. The orientation of the occlusal plane is assessed on the basis of the curve of Spee in regard to the anteroposterior dimension, and on the basis of the curve of Wilson frontally (Fig. 4). In cases of posterior cross-bite with an increased curve of Wilson, it is very difficult or impossible to achieve proper occlusion with orthodontic, orthopaedic or even surgical maxillary expansion. The solution for such cases is maxillary expansion with multiple section osteotomies. Buccal inclination of posterior lower teeth is often associated with macroglossia or tongue protrusion (Wolford et al., 2004).

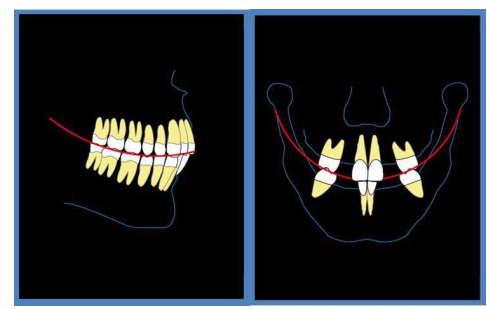

Fig. 4. The curve of Spee and of Wilson 
Assessment of the width of the upper and lower dental arches is performed by measuring the inter-canine, inter-premolar and inter-molar distances and comparing them with the recommended normal values, which, however, is purely indicative in nature and changes depending on race and an individual's size. Disorders in the transverse plane affect preoperative orthodontics and determine the surgical treatment necessary. A practical way to reveal width discrepancies, as well as upper and lower arch discrepancies in general, is to mount the casts manually, so that the first molars are in Class I malocclusion.

Casts help us perform Bolton analysis, which is a method that compares the magnitude of the mesio-distal dimension of the upper and lower teeth. It may concern the anterior teeth or the whole set of teeth of the two arches. If there are discrepancies in tooth width, alignment and intercuspation are obstructed. Such disorders are usually caused by small upper lateral incisors or wide lower ones. Along with Bolton analysis, one should take into account the incisors' labiolingual width and their axial inclination. Assessing tooth size discrepancies is very important because this is also a factor determining the goals of presurgical orthodontics and surgical treatment. An even more accurate assessment is possible with a diagnostic wax set up on the casts.

A pair of casts is mounted on an anatomical articulator with facebow record, although a hinge articulator might be suitable for cases that require only mandibular surgery. The need to mount casts during the initial stages of treatment planning is a controversial issue, but may be necessary if maxillary impaction is being planned, so as to define the effect of mandibular autorotation. In cases of significant displacement, it might also be useful to mount casts in central occlusion so as to help treatment planning. In most cases, however, it is sufficient to use manual mounting of casts so as to determine arch intercuspation, avoiding the need of a facebow record (Winchester \& Young, 2007).

\subsection{Photographs}

Photographs are an auxiliary tool for the clinical examination and cephalometry when investigating the aesthetic and functional restoration of the dentition and the face. Initially, two frontal photographs should be taken, one with the lips at rest position and one with the person laughing; then a $3 / 4$ photograph of the face and a profile photograph should taken. In cases of asymmetries, it would be useful to take photographs of both profiles. In order to make better use of extra-oral photographs, hair, beard and moustache should be removed from the face. Intra-oral photographs should include anterior teeth and the left and right buccal segments parts in occlusion as well as photographs of the occlusal surfaces of the upper and lower arch using a mirror. Photographs sometimes provide a more objective view than clinical examination, particularly in cases of asymmetry. Photographs should be taken before and after surgery to help the intervention or to serve teaching purposes; rarely, they might also be used for medico-legal purposes.

\subsection{Radiographs}

In order to plan an orthognathic case, it is necessary to have a panoramic and a lateral cephalometric radiograph. The overview of the panoramic radiograph indicates the presence of pathological conditions, such as impacted teeth that have not erupted, congenitally missing teeth or supernumerary teeth, caries, periodontal disease, apical lesions or cysts as well as the inclination or course of dental roots. The panoramic radiograph provides images of various forms of the mandibular open or closed angle as well as the 
relative position, morphology and integrity of the condyles (Fig. 5). In cases of condyledamage, the radiograph should be complemented by axial tomography or even three dimensional scans of the temporomandibular joint (3 - dimensional CT scan) (Kapila et al., 2011). Periapical radiographs are useful for a more accurate evaluation of inter-root spaces, when inter-dental osteotomies are to be performed. An occlusal radiography is often useful to clarify regions with a particular pathology, e.g. in order to locate the position of impacted teeth and to determine bone deficits in cleft cases.

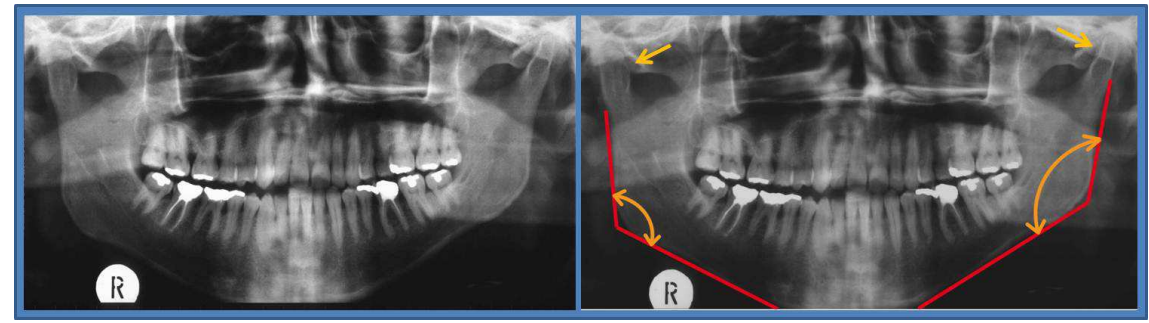

Fig. 5. Panoramic radiograph of a patient with asymmetry

\subsubsection{Lateral cephalometric radiograph}

Cephalometric analysis performed on the lateral cephalometric radiograph provides details about skeletal structure relationships as well as relationships between skeletal structures and the teeth and facial soft tissues, which cannot be observed in any other way. The catalytic role of such imaging on the complexity of the stomatognathic system and the knowledge of the functional impact of various facial patterns has been included not only in orthodontics but in other fields as well, such as orthognathic surgery.

Although cephalometric analysis is extremely useful to provide information concerning the diagnosis and treatment plan, this is not an absolutely exact scientific method (Baumrind \& Frantz, 1971). Furthermore, it should not be considered as a primary diagnostic tool; it should be considered that the treatment aims are a proportional and harmonious facial structure, without necessarily aspiring at ideal cephalometric measurements. When there are significant discrepancies between clinical evaluation and cephalometric analysis data, the clinical assessment is much more significant in preparing the treatment plan (Chaconas \& Fragiskos, 1991). Today there is a wide range of cephalometric radiograph analysis methods, which are either linear-descriptive or structural ones (Muller, 1962). Cephalometric radiograph analysis methods are usually based on measurements, which are compared to corresponding ones within normal range; this, however, presents inherent difficulties (Ricketts, 1975; Sassouni 1971), due to racial or ethnic differences, age and gender differences, possible differences in radiographic techniques (orientation in regard to the horizontal Frankfurt plane or in accordance to the natural head position) or differences that concern the criteria for selecting the 'normal' sample, such as occlusal features and skeletal background, at any given time (Miethke, 1995). In essence, though, what is important is whether there is harmony or discrepancy between the functional structures of the craniofacial complex in the same individual rather than the agreement of cephalometric data of the individual under study when compared to the normal sample range, as this was defined by the researcher at any given time (McNamara \& Brudon 1993; Sassouni, 1971). Linear and descriptive analysis in lateral cephalometric radiographs is based on the study of 
jaw relationships with the cranial base and each other, the relationships of teeth with each other and their corresponding bone bases and the relationships of soft tissues in the profile view of the face. Measurements performed concern the maxilla, the mandible, the teeth and soft tissues.

\subsubsection{Maxillary measurements (Fig. 6)}

1. The S-N-A Angle: this provides an indication about the anteroposterior position of the maxillary base in relation to the anterior cranial base. Its normal value is $82^{\circ} \pm 2$ for men and $81^{\circ} \pm 2$ for women. A high value indicates a protruding maxilla, while a low one a retrusive maxilla. 2. The angle formed by the Frankfurt plane and the line defined by the nasion and point $\mathrm{A}$. This is called maxillary depth and its mean value is $90^{\circ} \pm 3$. This angle indicates the anteroposterior position of the maxilla in relation to the horizontal plane. Skeletal Class II type caused by the maxilla presents values over $90^{\circ}$, while, Class III types present lower values. This angle also presents lower values in cases of palatal clefts. 3 . The distance of point A from the McNamara line (drawn through point $\mathrm{N}$ perpendicularly to the horizontal Frankfurt plane): this indicates the position of the maxilla in relation to the anterior part of the skull and, normally, point A lies near this line. Values above $+3 \mathrm{~mm}$ indicate maxillary protrusion, while values under $-3 \mathrm{~mm}$ indicate maxillary retrusion. Anteroposterior maxillary assessment should also take into account that the position of point $\mathrm{A}$ is affected by potential alveolar protrusion and by any pronounced inclination of the upper incisors. 4 . The N-CF-A Angle (CF is the intersection point of the Frankfurt plane with the PTV plane). This is called maxillary height and its mean value is $56^{\circ} \pm 3$. It indicates the vertical position of the maxilla in the face. In cases of skeletal open bite caused by the maxilla, the values of this angle are low, which indicates a short upper face.

\subsubsection{Measurements concerning the mandible (Fig. 6)}

1. The S-N-B Angle. This indicates the anteroposterior position of the mandible in relation to the anterior base of the skull. Its normal value is $80^{\circ} \pm 2$ for men and $78^{\circ} \pm 2$ for women. A high value indicates a protruding mandible, while a low value a retrusive one. It should be taken into account that the values of the S-N-A and S-N-B angles are influenced by the inclination and lenght of the anterior cranial base S-N. 2. The facial angle, formed by the Frankfurt plane and the facial plane N-Pg. Its mean value is $90^{\circ} \pm 3$. This angle assesses the anteroposterior position of the mandible and determines whether a skeletal Class II or III is caused by the mandible. 3. The distance of point Pg from the vertical line going through point $\mathrm{N}$. This indicates the anteroposterior position of the mandible in relation to the base of the skull. Normally, its values range from $-4 \mathrm{~mm}$ to $0 \mathrm{~mm}$ for individuals of medium facial size (McNamara, 1984). Among adults, point Pg usually lies $2 \mathrm{~mm}$ behind this line. Values under $-5 \mathrm{~mm}$ indicate a retrusive mandible, while values above $+3 \mathrm{~mm}$ indicate a protrusive maxilla (Stroud, 1997). 4. The angle formed by the mandibular plane (Go-Me) and the Frankfurt plane. This is the FMA Angle of Tweed. Its mean value is $25^{\circ} \pm 4$. This angle provides an indication as to the vertical height of the mandibular ramus and the posterior facial height. This measurement indicates the vertical type of the face. An open angle indicates a long face and, in cases of skeletal anterior open bite, that it is caused by the mandible. On the contrary, a closed angle indicates a short type of face and in cases of skeletal deep bite this is caused by the mandible. A high value indicates a long and narrow face with narrow dental arches. On the contrary, patients with a small angle tend to have a relatively high posterior facial height and increased activity of the masticatory muscles. Furthermore, they have a tendency for an overbite and muscular spasm particularly of the 
temporalis and the medial pterygoid muscle, predisposing for TMJ problems (Chaconas \& Gonidis, 1986).

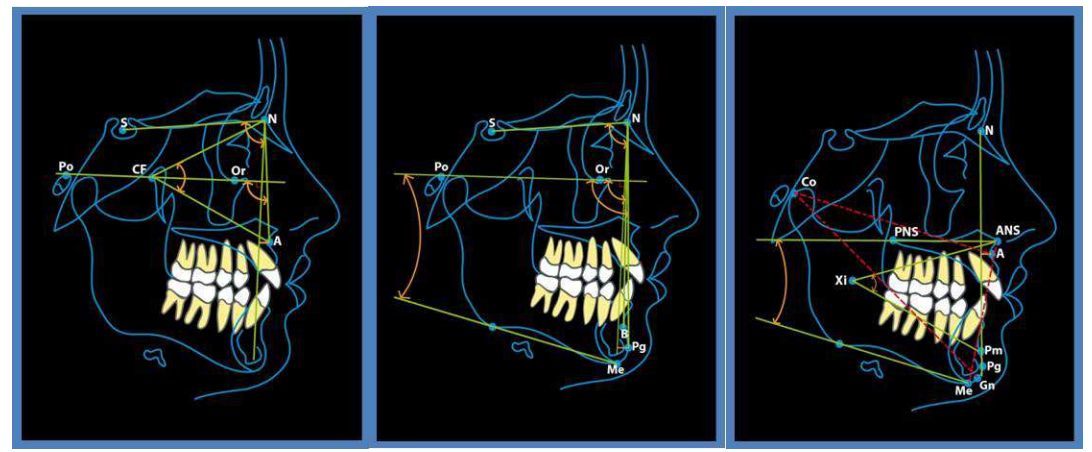

Fig. 6. Cephalometric measurements concerning maxilla, mandible and their relationship

\subsubsection{Measurements concerning the relationship between maxilla and mandible (Fig.6)}

1. The convexity of the face, which is the distance of point A from the facial plane N-Pg. Its mean value among adults is $1.7 \mathrm{~mm} \pm 2$. If point $\mathrm{A}$ lies in front of the $\mathrm{N}-\mathrm{Pg}$ line, then the profile is convex and it is a skeletal Class II case, either because the chin is retrusive or because the maxilla is protruding or because there is a combination of the two. On the contrary, if point A lies behind the N-Pg line, then the profile is concave and the case is one of skeletal Class III, either because the chin is protruding or because the maxilla is retrusive or because the two conditions co-exist. The highest acceptable convexity among adults is 4 mm (Langlande, 1981). 2. The ANS-Xi-Pm angle indicates the lower facial height. Its mean value among adults is $47^{\circ} \pm 4$. If this angle value is higher, it indicates the presence of open bite, while a lower value indicates the presence of deep bite. 3 . The angle formed by the maxillary plane (ANS-PNS) and the mandibular plane (Go-Me). Its mean value is $27^{\circ} \pm 4$. This angle is important because it indicates the posterior facial height and reflects the surgically significant pterygo-masticatory muscle and ligament height. For example, a patient with a high value for this angle, e.g. exceeding $35^{\circ}$, tends to have a relatively short posterior facial height and, therefore, an equally short posterior height of the muscles and ligaments involved. Any attempts to stretch this posterior connective tissue by rotating the anterior mandibular body upwards, in an anti-clockwise direction, around a fulcrum formed by the posterior molar occlusion is condemned to fail and lead to early surgical relapse (Hunt, 2008a). It should be noted here that the position of the mandible is not only affected by its size and its position due to the inclination of the cranial base, but also by the vertical dimension. For example, if the vertical dimension is excessive, the mandible might appear to be insufficient in relation to the maxilla. Therefore, it would be relatively retrusive, but only due to the vertical dimenstion. The opposite would be true in vertical deficits. If the vertical dimension is not normal, additional measurements often help clarify the analysis (Stroud LP. (1997), such as those recommended in McNamara's method. McNamara's method (McNamara, 1984) attempts to individualise patients, given that there is indeed a stable linear relationship between the relative length of the maxilla (distance between Condyle Co, i.e. the most superior lateral point of the mandibular condyle, and point A) and the relative length of the mandible (distance between the Condylium Co from the anatomical Gn). For 
every relative length of the maxilla of a specific individual, there is one relative length of the mandible within a given width. This relationship also takes into account the vertical dimension, as this is defined by the anterior lower facial height (ANS-Me) (Fig. 6). In other words, what is characteristic about the McNamara method is the presence of the triangle formed by the maxilla, the mandible and the anterior lower facial height and their interrelationship as shown in the tables of composite values resulting from the combination of the three cephalometric samples (Table 1). So, the "originality" of this method lies in the fact that it directly correlates maxillary and mandibular lengths with lower facial height, regardless of the gender or the age of an individual. This leads to a useful combination of measurements with the substantial advantage of using it for diagnostic and therapeutic purposes in cases of skeletal problems, particularly when a combination of orthodontic treatment and orthognathic surgery is required (Sinclair \& Proffit, 1991).

\subsubsection{Measurements concerning dental relations (Fig. 7)}

1. The angle formed by the lognitudinal axis of the upper incisor and the palatal plane $\left(\underline{1} /\right.$ ANS-PNS). Its mean value is $109^{\circ} \pm 5$. In cases of Class III dentoalveolar disorder, this angle often presents increased values, since the incisors have an increased labial inclination in order to compensate for or alleviate the malocclusion present. 2 . The angle formed by the lognitudinal axis of the upper incisor and the anterior cranial base ( $1 / \mathrm{S}-\mathrm{N})$. Its mean value is $103^{\circ} \pm 2$. This angle becomes particularly significant in cases when the palatal plane is to surgically change inclination, as in some open bite cases. In these cases, its coassessment with Angle 1/ANS-PNS indicates to the orthodontist the necessary preoperative movement of upper incisors. 3. The distance of the labial surface of the upper incisor from a vertical line going through point $\mathrm{A}$ and drawn so as to be parallel to the vertical line going through the nasion. This measurement determines the anteroposterior position of the upper incisor in relation to the mandible. Its mean value is $4-6 \mathrm{~mm}$. Upper incisor positions more posterior than $1 \mathrm{~mm}$ to this line are considered to be lingual positions, while upper incisors situated more than $7 \mathrm{~mm}$ anterior to this line are prominent incisors. 4. The angle formed by the lognitudinal axis of the lower incisor and the mandibular base plane ( $\overline{1} / \mathrm{Go}-\mathrm{Me}$ ). Its mean value is $90^{\circ} \pm 5$. This angle indicates the anatomical position of the lower incisor in relation to the base of the mandible. A reduced value of this angle is almost always encountered in Class III malocclusion cases, as a compensatory factor. However, in cases of Class II malocclusion, this angle is increased (Guariglia \& Ronchi, 2005). 5. The angle formed by the lognitudinal axis of the lower incisor and the dentoalveolar plane A-Pg (i / A-Pg). Its mean value is $22^{\circ} \pm 4$. This angle indicates the inclination of the lower incisor in relation to the

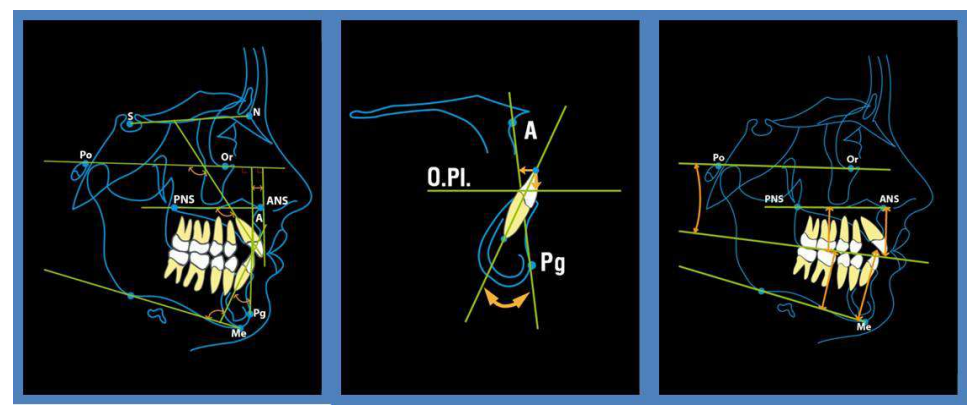

Fig. 7. Cephalometric measurements concerning dental relationships 
dentoalveolar plane A-Pg and it adapts to the facial skeletal type; it is increased in short facial types and decreased in long types. 6 . The distance of the lower incisal edge from the dentoalveolar plane A-Pg ( $(\overline{1} \rightarrow \mathrm{A}-\mathrm{Pg})$. Its mean value is $2.4 \mathrm{~mm} \pm 2$ and it indicates the projection of the lower incisor. Incisors lying more than $5 \mathrm{~mm}$ in front of the line are protruding, while incisors behind the line are retrusive. 7 . The distance of the lower incisal edge from the occlusal plane. Its mean value is $1.25 \mathrm{~mm} \pm 2$ and it indicates overeruption of the lower incisor; it shows whether the abnormal deep bite is due to theintrusion orextrusion of the lower or upper incisor (Ricketts, 1982). 8. The distance of the upper incisal edge from the palatal plane ( $1 \rightarrow$ ANS-PNS). Its mean value is $33 \mathrm{~mm} \pm 3$ and it indicates the anterior dentoalveolar height. 9. The distance of the lower incisal edge from the mandibular plane ( $\overline{1} \rightarrow \mathrm{Go}-\mathrm{Me})$. Its mean value is $44 \mathrm{~mm} \pm 2$ for men and $40 \mathrm{~mm} \pm 2$ for women. It indicates the lower anterior dentoalveolar height. It should be noted that these measurements of the anterior upper and lower dentoalveolar height reflect aspects of the lower height of the face. In other words, if the anterior lower height of the face is increased, then the upper and lower anterior dentoalveolar height will also be increased, with the exception of some open bite cases. (Hunt, 2008a). 10. The distance of the tip of the medial cusp of the lower first molar from the mandibular plane $(\overline{6} \rightarrow \mathrm{Go}-\mathrm{Me})$. Its mean value is $38 \mathrm{~mm} \pm 3$ and it indicates the posterior lower dentoalveolar height. 11. The distance of the tip of the medial cusp of the upper first molar from the palatal plane ( $\underline{6} \rightarrow$ ANS-PNS). Its mean value is $28 \mathrm{~mm} \pm 3$ and it indicates the posterior upper dentoalveolar height. Low values of the upper and lower posterior dentoalveolar height might indicate ankylosis or eruption failure. On the contrary, high values indicate supraeruption and are blamed for skeletal anterior open bite (Langlande, 1986). 12. The angle formed by the occlusal plane and the horizontal Frankfurt plane. The occlusal plane is defined by points corresponding to the middle of the overlapping of the cusps of premolars and molars. Mean angle value is $8^{\circ} \pm 4$ and it indicates the inclination of the occlusal plane. This plane is very important from a functional point of view, in relation to mandibular movement. Along with the anterior and posterior decisive factors for occlusion, it determines how teeth get disengaged (Stroud, 1997). The occlusal plane has a significant impact on function and aesthetics, particularly in cases of bimaxillary osteotomy (Wolford, 2007).

\subsubsection{Measurements concerning facial soft tissues (Fig. 8)}

1. The ratio of the middle third to the lower third of facial soft tissues is $1: 1$. The middle third is the distance determined by points Gs (the most anterior part of the forehead corresponding to the glabella) and Sn (the most posterior point of the nasal base, where it joins the upper lip). The lower third is the distance defined by points $\mathrm{Sn}$ and Mes (the lowest point of chin soft tissues). In most orthognathic surgery patients, abnormalities are located in the lower third of the face, which is increased in relation to the middle third, either due to vertical excess of the posterior maxillary region or due to increased anterior vertical height of the mandible. In cases of reduced lower third of the face, the cause expected is either vertical maxillary hypoplasia or reduction of the anterior vertical height of the mandible or forward rotation of the mandible (Reyneke, 2003). 2. The length and eminence of the nose is the projection of the Sn - Pn distance on a straight line parallel to the horizontal Frankfurt plane and going through point $\mathrm{Sn}$. Its mean value is $18 \pm 2 \mathrm{~mm}$. Aesthetically it is more acceptable for women to have less eminent noses than men (Lines et al., 1978). When planning maxillary osteotomy, the impact it might have on the nose should be taken into account. 3. The distance of the subnasal point Sn from point Sts (the lowest point of the 
upper lip) is the upper lip height. Its normal value is $22 \pm 2 \mathrm{~mm}$ in men and $20 \pm 2 \mathrm{~mm}$ in women. If measurements indicate values below normal ones, then the upper lip is short. The upper lip height is a decisive factor for the vertical dimensions of the lower third of the face, because it represents one third of this distance and because it is not easy for the upper lip height to change. This measurement is the basis that can determine the vertical height of the lower two thirds of the lower third of the face.

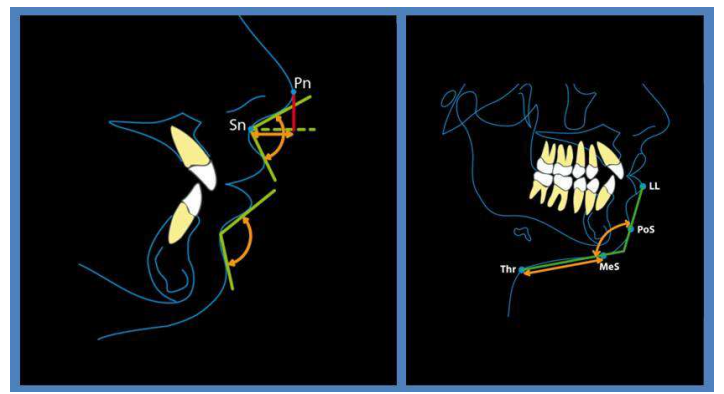

Fig. 8. Measurements concerning facial soft tissues

4. The distance of point Sts from the upper incisal edge, when the lips are at rest. Its normal value is $2.5 \pm 1.5 \mathrm{~mm}$ (Arnett \& Bergman, 1993; Fish \& Epker, 1980; Miethke, 1995; Proffit, 1993). This measurement is affected by the upper lip height, the height of the maxilla, the height of the upper incisal crown, the thickness of the lips and the inclination and anteroposterior position of the upper incisors. This assessement is particularly important when determining the vertical dimensions of the face, particularly when there are vertical maxillary dysplasia (Wolford, 2007). Lack of upper incisor exposure might indicate vertical maxillary hypoplasia, while exposure exceeding $4 \mathrm{~mm}$ may indicate vertical maxillary excess, if the the upper lip height is normal (Reyneke, 2003). 5. The nasolabial angle, formed by a tangent on the columella which goes through the subnasal point $\mathrm{Sn}$ and a straight line connecting point $\mathrm{Sn}$ with the most anterior point of the upper lip (UL). An angle of $85^{\circ}-105^{\circ}$ is considered normal and this value varies depending on race (Burstone, 1967; Lines et al., 1978). The angle is usually acute in Class III cases, while Class II patients present a more obtuse nasolabial angle. A straight line going through point $\mathrm{Sn}$ and parallel to the horizontal plane separates the nasolabial angle into a superior and an inferior part. The upper/lower nasolabial angle ratio is of particular importance and should be one to four (Fig. 8). Ratios above $25 \%$ indicate an eminent upper lip or an upward tipping nose. On the contrary, lower ratios may indicate a retrusive upper lip or reduced eminence of the nose tip (Stella \& Epker, 1990). It should be taken into account that when the maxilla is surgically shifted upward and backward, this causes loss of upper lip support, an increased nasolabial angle and flattening of the nose, which results in bad aesthetics due to a premature aging effect. 6 . The mentolabial angle, formed by the straight line that goes through the most posterior point of the mentolabial sulcus (Sm) and it is tangent to the lower lip and the chin tangent that also goes through point $\mathrm{Sm}$. Its mean value is $130^{\circ} \pm 10$, with lower values preferable for men than for women. This angle is usually acute in Class II cases with anteroposterior mandibular hypoplasia, due to the pressure exercised by the upper incisors on the lower lip or in cases of macrogenia. The angle is flattened in microgenia cases or due to lower lip tension in Class III malocclusion cases. When planning genioplastic osteotomy, what should 
be considered is not only the anteroposterior position of the chin but also the menton shape and the mentolabial sulcus. 7. The mentocervical angle, formed by the straight line going through the most posterior point of the menton (PoS) and the most anterior point of the lower lip (LL) and a straight line going through the lowest point of the menton (MeS) and the neck-throat joint point (Thr). The mean value of this angle is $110^{\circ} \pm 8$. It is more acute in skeletal Class III cases and less acute in skeletal Class II cases, in which mandibular disorders are involved. 8. The throat length is the distance between the neck-throat joint point (Thr) and the lowest point of the menton (MeS). Its mean value is $40 \pm 5 \mathrm{~mm}$. The throat length is increased in cases of mandibular macrognathia and it is shorter in cases of mandibular micrognathia. This measurement is useful to ensure differential diagnosis between anteroposterior mandibular excess and maxillary hypoplasia. The menton-throat angle and the throat length are of particular importance when planning surgical anteroposterior shift of the mandible, genioplastic osteotomy (protrusive or reductive) or submental liposuction. Thus, in individuals with a short throat length and mandibular protrusion, backward surgical shift of the mandible would be particularly unaesthetic (Proffit, 1991). To ensure proper assessment of these measurements, radiographs should be taken in the natural head position. 9. The eminence of the upper and lower lips and the chin are assessed on the basis of distances of points UL, LL and PoS from a straight line that goes through point $\mathrm{Sn}$ and is perpendicular to the Frankfurt plane. Mean values of these distances are as follows: $2 \pm 2 \mathrm{~mm}$ for the upper lip, $0 \pm 2 \mathrm{~mm}$ for the lower lip and $-3.5 \pm 2 \mathrm{~mm}$ for the chin (Bass, 1991: Fish \& Epker, 1980; Wolford, 1990). The eminence of the lips, according to Ricketts are the distances of points UL and LL from the aesthetic plane PoS-Pn. Normally, the lips lie behind the aesthetic plane: the upper lip at $4 \mathrm{~mm}$ and the lower lip at 2 $\mathrm{mm}$. These measurements indicate the balance or lack of balance of the soft tissue between the lips and the nose - chin profile (Ricketts et al., 1982).

\subsubsection{Cephalometric prediction of surgical orthodontic treatment}

Cephalometric prediction of the surgical orthodontic treatment outcome allows the direct visualization of both dental and skeletal movement and projects the probable post-surgical patient profile. It can be of assistance to both orthodontists and maxillofacial surgeon in planning the treatment and to patients in comprehending postoperative changes and, mainly, the change in the appearance of their faces. Various manual cephalometric methods have been proposed (Fish \& Epker 1980; McNeil et al., 1972; Proffit, 1991; Wolford et al., 1985; Worms, 1976). Manual cephalometric techniques are implemented either using the overlay method or templates. The overlay method by Proffit (Proffit, 1991) is the simplest prediction method for mandibular osteotomies; it is restricted to surgeries that do not affect the vertical position of the maxilla and is not time consuming. These are its stages, in brief (Fig. 9) : a) drawing the initial cephalometric tracing (CT) and the surgical reference line; b) a second acetate paper is placed over the initial tracing, so called the overlay tracing; Drawing on the overlay tracing the skeletal structures that are not going to change during surgery, including the surgical reference line; c) Movement of the CT mandible backward, on the overlay so as to achieve the desirable overjet and overbite and the proper intercuspation of posterior teeth. Drawing on the overlay the lower teeth and the part of the mandible in front of the surgical line; d) Superimposition on the cranial base and measurement of the backward movement of the lower incisor and skeletal chin movement; calculation of the predicted position of the lower lip and soft chin, using data regarding ratios of soft tissue changes relative to respective skeletal movements (the response of the lower lip represents $60 \%$ of skeletal changes, while the chin response is absolute, i.e. 1:1) 
(Jensen et al., 1992). Measurement of the distance between the surgical reference lines to determine the surgical movement in millimetres; e) Superimposition at the mandible and drawing the lower lip outline and the chin; f) Superimposition at the cranial base; drawing the predicted soft tissue profile. The template method is implemented in all types of osteotomy and it is very useful in repositioning of the chin and almost necessary when the maxilla is plan to be moved on the vertical plane. However, the implementation of this method is timeconsuming. In cases of one or two pieces osteotomies, the entire maxilla outline is drawn while in three-piece osteotomies an outline of the anterior and posterior maxillary pieces and the mandibular outline are drawn. The mandible rotates around the condyle (Proffit \& Sarver, 2003).

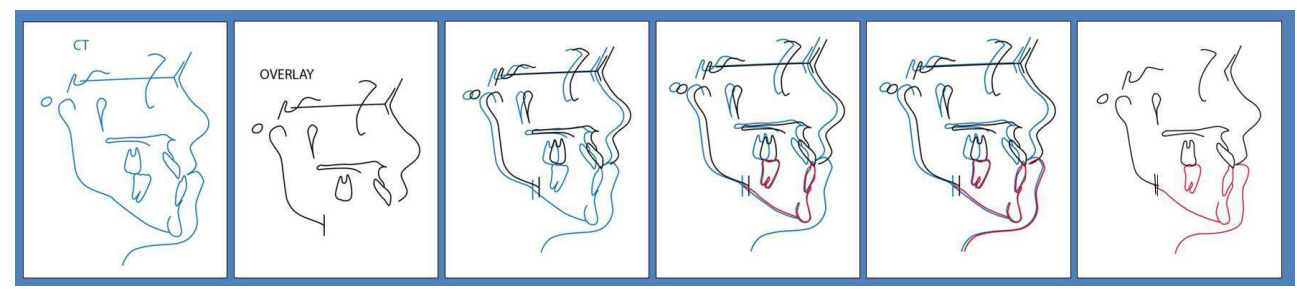

Fig. 9. The stages of Proffit's overlay method

Cephalometric prediction using a computer presupposes digital tracing of the cephalometric radiograph; it can be performed either by using software programmes alone or a combination of software and video images (Athanasiou \& Kragskov, 1995). The operator shifts the cursor to various points, depending on the type of surgery, until the desirable aesthetic outcome is achieved. Then the predicted postoperative profile is printed and surgical movements can be calculated on it. This way, it is possible to save and analyse graphic data, to diagnose and plan the orthognathic cases as well as to predict the patient's postoperative profile. Computerized cephalometric prediction combined with video images is performed through automatic superimposition of the cephalogram on the patient's profile by the software programme, which is visible on the video monitor. All movements are of actual size. Today three-dimensional prediction methods are available. Computer prediction facilitates physician-patient communication, but there are certain inaccuracies involving mainly the lip area and the chin region (Eales et al., 1994; Kaipatur \& Flores-Mir, 2009; Kolokitha et al., 1996; Kolokitha, 2007).

\subsubsection{Anteroposterior cephalometric radiography}

Anteroposterior analysis based on cephalometric radiographs is mainly useful for studying transverse asymmetries of the craniofacial complex. This analysis provides information about the width and inclination of the dental arches in relation to their osseous bases at the transverse plane. The analysis also provides an opportunity to assess the width of transverse maxillomandiubular relations and the vertical dimensions of corresponding skeletal parts or points of the dentition of the two facial halves and the nasal cavity, while analysing any asymmertries at the transverse or vertical planes. The study of facial symmetry is not always a mathematical measurement, according to certain authors. The symmetry can also be 'roughly' assessed, i.e. just by looking at the face. Vion considers it easier to assess asymmetry by placing the tracing on millimetre graph paper (Vion, 1976). Ricketts recommends the use of measurements, the most important of which for orthognathic 
surgery candidates are the following (Ricketts, 1982) (Fig. 10): 1. The distance between the maxilla (zygomatic process) and the frontal facial plane (JR $\rightarrow \mathrm{ZR}$ ) and (JL $\rightarrow \mathrm{ZL}$ ). Its mean value for adults is $15 \pm 1.5 \mathrm{~mm}$ and it indicates the left and right width of the maxilla and the mandible. It determines whether posterior cross-bite is skeletal. High values indicate skeletal lingual cross-bite, while low values indicate skeletal buccal cross-bite. 2 . The angle formed by the maxillary midline (ANS - middle of ZR - ZL) and the mandibular midline (ANS - Me). Its mean value is $0^{\circ} \pm 2$. In cases of asymmetry, this angle determines whether it is caused by dental or skeletal causes or by functional shift of the mandible. When the two midlines coincide there is symmetry and they both go through the incisal contact points. 3 . The difference between the height of the occlusal plane at the left and right molars, measured in relation to the ZR - ZL line. Its mean value is $0 \pm 2 \mathrm{~mm}$. Deviation from the mean value indicates asymmetry accompanied by structural abnormality of the maxilla or the mandible or both jaws. True skeletal asymmetry accompanied by an inclined occlusal plane is usually a warning sign for TMJ dysfunction. 4 . The difference between the right and left angles, formed by points ZR-GA-AZ on the right and ZL-AG-ZA on the left. Its mean value is $0^{\circ} \pm 2$. It indicates the position of the mandible and helps explain the nature of the asymmetry. Where the difference exceeds $4^{\circ}$ it should be examined whether the asymmetry is of a structural or functional aetiology. These angles are significantly affected by a head turn on the headrest. Langlande also recommends the use of the distance between point DC (top of the condyle head) and the corresponding anti-gonion point AG, as well as the distance between point $\mathrm{Me}$ and the corresponding anti-gonion point so as to assess asymmetry (Fig. 10). These measurements make it possible to judge whether the asymmetry is due to the ramus or the body of the mandible (Langlande, 1981).

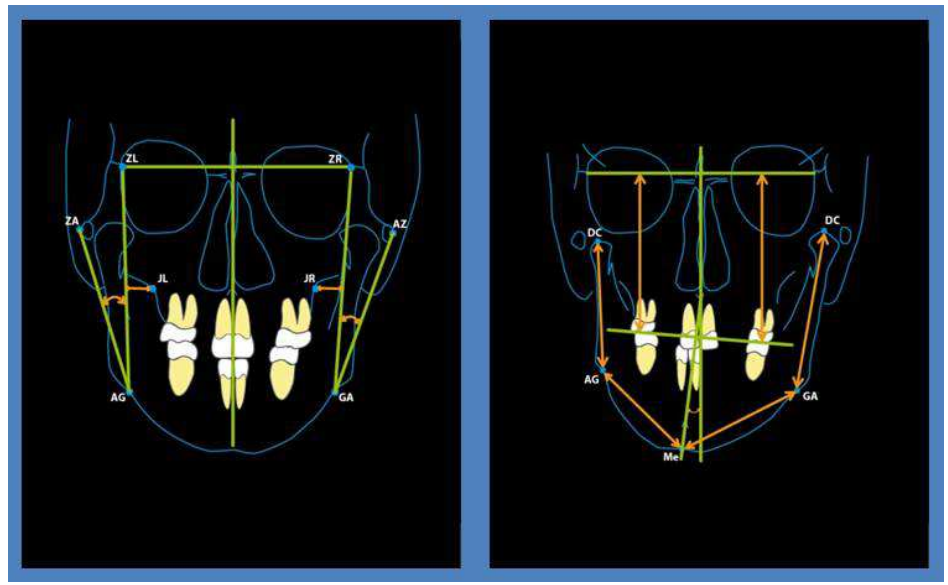

Fig. 10. Measurements concerning anteroposterior cephalometric radiographs

\section{Preoperative orthodontics}

The goals of preoperative orthodontic treatment are to allow for maximum surgical correction of the abnormality, to facilitate potential sectional surgical procedures and to provide the possibility for creating an ideal, stable occlusion (Tompach et al., 1995). The major part of orthodontic treatment takes place before surgery and might last one and a half 
to two years (Slavnic \& Marcusson, 2010; Diaz et al., 2010). However, there are those who prefer to leave the major part of orthodontic treatment for after the surgery. Extensive preoperative treatment and limited postoperative treatment is usually better tolerated by the patient and provides smoother cooperation (Lee, 1994). The goals of preoperative orthodontic treatment are achieved with the alignment and flattening of the arches, the exacerbation of dental relations by removing all dentoalveolar compensation for the skeletal abnormality and with arch coordination.

\subsection{Arch alignment}

The first goal of preoperative orthodontics is to align the dental arches or their parts so that they might be compatible with each other. Correcting crowding and rotations, management of impacted teeth and arch length discrepancies is mainly a concern of preoperative orthodontics, because it facilitates arch intercuspation; otherwise, the surgical result would be restricted. If arch length is to be reduced, and the incisors need to be shifted backwards, then extractions are performed, as, for example, in Class III cases, when the upper incisors need to be moved backward or in Class II cases, when the lower incisors have to be moved backward to achieve exacerbation (Proffit \& White, 1991) (Fig. 11). When sectional surgery is being planned, the deviation of dental roots close to the osteotomies starts with the initial wire and it is monitored through periapical radiographs. The modern preconstructed brackets of fixed devices and straight Ni-Ti wires have significantly simplified modern orthodontics. Selecting the slot size is a matter of personal preference, although the 0.022 inch system can better immobilise intraoperatively with rigid $19 \times 25$ wires. Ceramic brackets are pleasant, because they provide aesthetic solutions; however, their disadvantage is that they break easily during surgical manipulations. Most preconstructed bracket systems have been designed to tip the roots of canines distally and, thus, create sufficient space between them and the roots of lateral incisors.

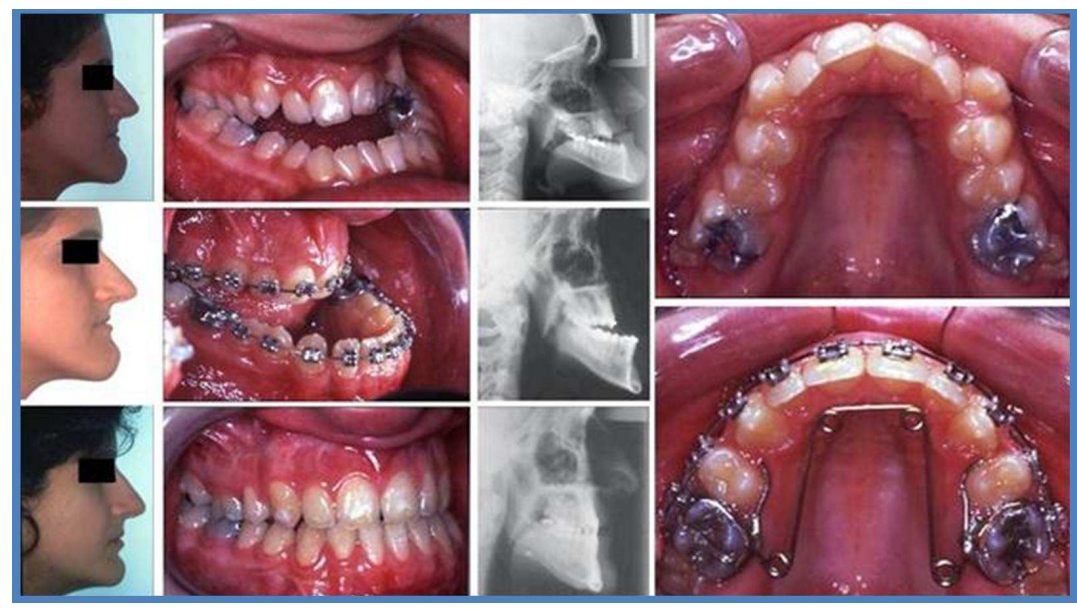

Fig. 11. A Class III case, with preoperative extractions of the first upper premolars to manage crowding and to move the upper incisors in order to achieve exacerbation of the negative overjet, which was completed with labial tipping of the lower incisors

This space is useful in cases where interdental osteotomies are to take place in the maxilla. When osteotomy incisions are performed distally to the canines, the use of brackets on the 
contralateral canines warrants that the integrated distal tipping of the brackets keeps the apices anteriorly and outside surgical incisions (Hunt, 2008b).

\subsection{Arch flattening}

The planning of dental arch flattening is particularly important. The general principle is that extrusion is easier postoperatively, while intrusion needs to be completed preoperatively or intra-operatively. Dental flattening and alignment are ususally a common one-step process in conventional orthodontics. This is not the case for all surgical cases. When the mandible is surgically moved forward or backward, the position of the lower incisor is what determines the lower facial height. In surgical correction of Class II, when the lower facial height is reduced, it is preferable not to correct the curve of Spee in the lower dental arch, either through orthodontics or surgically. Surgical protrusion of the mandible creates lateral open bite and a tripod-like occlusal relation; only the last molars and incisors are in an occlusal relationship. Besides, the lower facial height increases as the chin moves downward. Before the operation, the teeth are aligned and the anteroposterior relationship of the incisors has been determined. However, the curve of Spee remains in all wire arches, including the final stabilising wire (Proffit \& Fields, 2007). The lateral open bite is treated with extrusion of the teeth involved, using vertical elastic forces during postoperative orthodontics. Numerous clinicians think that $2 \mathrm{~mm}$ of extrusion in every arch is the maximum that may be achieved and remain stable without relapse (Hunt, 2008b). If the intentional lateral open bite that remains after surgery is deemed to be too much, then the curve of Spee will have to be reduced preoperatively, with the inevitable limitation that the increment of the lower anterior facial height will be limited postoperatively.

If the incisors are intruded preoperatively in a patient with deep bite, the operation tends to move the mandible upwards at the chin and downwards in the menton region, due to pivot effect. This increase of the posterior facial height will stretch the masticatory muscles (muscular stretching) and this is why it is unstable. However, when the incisors are not intruded preoperatively, the operation will move the chin downwards and the mandibular angle upwards, thus causing clockwise rotation of the mandible, which, generally speaking, is more stable in relation to the anti-clockwise mandibular rotation (Lake et al., 1981). (Fig. 12). On the contrary, when the lower facial height is increased, the pronounced curve of Spee has to be flattened preoperatively by intrution of the anterior part or surgically flattened with base osteotomy following sectional orthodontic flattening. Often a combined operation involving the maxilla is necessary to avoid the downward movement of the menton angle and further increase of the facial height, which is undesirable. If intrusion is necessary, the technique of sectional arches is indicated for preoperative orthodontics using mild forces in the order of $10-20 \mathrm{~g}$ per tooth, so that root resorption may be avoided, particularly if the teeth are fine. If this approach leads to lack of dental position control, it is preferable to have a continuous arch from molar to molar, with an anterior step for the incisors and canines. Continuous straight arches may achieve flattening, but probably with undesirable incisor tipping, which can be managed with extractions that allow the posterior movement of incisors. Surgical flattening is rarely indicated for the lower dental arch (Hunt, 2008b; Levander \& Malmgren, 1988). When surgically correcting open bite, in cases of increased lower facial height, it is preferable not to correct the curve of Spee preoperatively in the upper dental arch, since multiple section osteotomies are indicated in such cases. During preoperative orthodontics, the aim is to exacerbate open bite with extrusion of 
posterior teeth and intrusion of anterior ones. During the operation, the final flattening of sections takes place, which allows the forward rotation of the mandible. If a one piece Le Fort I osteotomy is decided, with greater intrusion of the posterior part of the maxilla, preoperative orthodontic flattening is required, but anterior teeth extrusion should be avoided before the operation, because even mild orthodontic relapse may cause postoperative opening of the bite (Proffit \& Fields, 2007). The importance of orthodontic movements of sectional flattening, which are usually unstable, is that it allows an attempt to minimise postoperative relapse. Following the removal of fixed orthodontic devices, the intruded incisors tend to infraocclude again and the extruded molars and premolars tend to intrude once again, thus compensating for the trend of the open bite to recur as a result of surgical relapse or undesirable growth rotation. (Houston, 1988; Lake et al., 1981). Sectional flattening is achieved if a step is made preoperatively to the upper wire arch at the occlusal plane or two lateral and one labial sectional arches are inserted. Other orthodontic devices that may be used are upper wire arches with increased curve of Spee, lower wire arches with inversed curve of Spee, inter-arch elastics to extrude posterior teeth, neck-traction headgear on the upper molars, J-pull headgear on the upper incisors or mini screws in order to intrude them (Winchester \& Young, 2007).

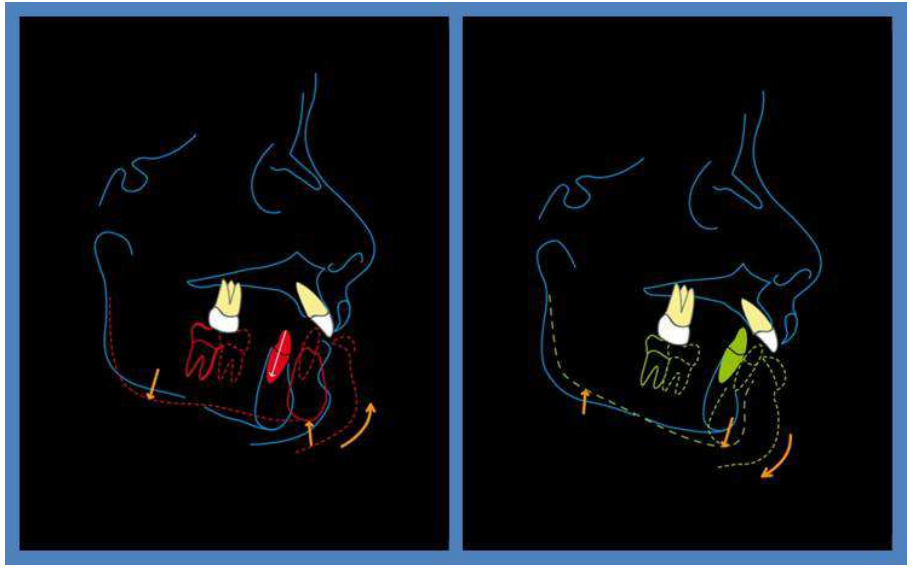

Fig. 12. Schematic representation of a Class II case surgical correction, where there is reduced lower facial height and the curve of Spee is pronounced. The red colour indicates chin and menton movements if the incisors are intruded (A) preoperatively and the green colour indicates what happens if they are not (B).

\subsection{Exacerbation}

In serious skeletal discrepancies, the teeth try to maintain some contact, under the effect of external and internal forces, so as to compensate for the skeletal problem. Although this compensation improves occlusal relationships and the patient's appearance, it restricts the extent of surgical correction. In skeletal Class III cases, the upper incisors are often labially inclined, while the lower ones are lingually inclined. On the contrary, in cases of skeletal Class II the upper incisors are often upright and the lower labially inclined. A consequence of these compensatory changes is that the overjet is virtual in regard to the actual magnitude of the skeletal discrepancy. Preoperative orthodontics aims at exacerbating dental 
relationships, by removing the camouflage effect and placing the incisors in normal inclination for the skeletal bases, if this is feasible (Jacobs \& Sinclair, 1983). (Fig. 20, 21) Removing compensation exacerbates the malocclusion preoperatively, but reveals the true magnitude of the skeletal problem, thus allowing optimal surgical correction without limitations or occlusal interference. So, if dental compensation from the incisors in Class II, type 1 cases is removed, twice as much forward movement of the mandible is possible, as opposed to what would have achieved if the compensation had not been removed. Similarly, in Class III cases, the mandibular backward movement allowed is five times as much when compensation is removed. (Fig. 13) (Worms et al., 1976). In Class II, type 1 cases, extractions of the first lower premolars may be performed to achieve exacerbation (Fig. 13) and Class III inter-gnathic elastic forces may be used. In Class III cases, there is often a small maxilla with crowding and the upper first premolars might have to be extracted along with the expansion, so as to achieve exacerbation. Furthermore, in Class III cases, when the goal is anteroposterior exacerbation, Class II inter-gnathic elastic forces may be used (Jacobs \& Sinclair, 1983). The use of Roth's brackets on incisors with increased crown torque might be an advantage in Class II cases, but undesirable in surgical Class III cases (Winchester \& Young, 2007). The exacerbation extent of the incisors is affected by postoperative skeletal stability; this means that full and extensive exacerbation might not always be the goal for a sound surgical outcome. In a Class III case, the exacerbation of the incisors might lead to such great discrepancy, that two-jaw osteotomy might be required for correction and a stable postoperative outcome; on the contrary, limited compensation might only need mandibular surgery. Furthermore, the extent of the exacerbation is restricted in cases of insufficient alveolar bone, when the roots of the incisors are fine or partly resorbed or if there are teeth with poor prognosis. When there is a very narrow attached gum zone or thin periodontium in the lower anterior region, it might be advisable to place a free gum graft before labial dental movement, so as to avoid resorption of the labial alveolar process and denuding of the roots (Boyd, 1978). In the case of maxillary depression at different levels, full exacerbation of the upper incisors is not necessary. The posterior region of the maxilla is depressed more than its anterior part. The consequence of such surgery is that the incisors are palatally inclined. So, when orthodontics is performed in this case, preoperative preparation migth intentionally leave the upper incisors with a slight labial inclination (Hunt N, 2008b).

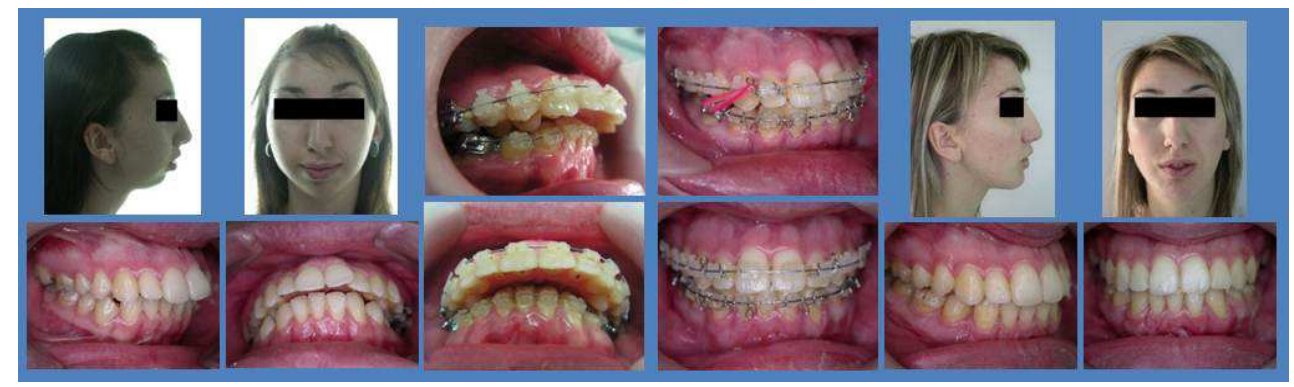

Fig. 13. A Class II case, where the lower anterior teeth, after extractions of the first lower premolars, were moved backwards to achieve exacerbation and allow forward surgical movement of the mandible. During postoperative treatment, Class II elastic forces were used to support sagittal correction. 


\subsection{Intercuspation of the two arches}

One of the goals of preoperative orthodontics is to achieve harmonisation of dental arches at all levels during surgery. Controlling dental arch harmonisation is initially achieved by the use of snap models (mounting the casts manually in occlusion) before surgery. Anteroposterior changes in skeletal relationships sometimes require modification in the transverse width of the arches, and expansion of the upper dental arch, in particular, so as to achieve harmonisation of intermolar and intercanine width. The way to achieve expansion depends on its magnitude and the initial bucco-lingual inclination of upper posterior teeth. Usually, this occurs spontaneously with the use of coordinated upper and lower continuous wire arches and the quad-helix device, which are useful for progressive expansion (Proffit \& White, 2003). The quad helix device might result in a deviating movement, but it has the advantage of allowing differential expansion in the right and left buccal sections. Rapid maxillary expansion is not recommended for adults, dut to potential risk for the roots and the periodontium, although surgically assisted rapid maxillary expansion may be performed (Barber \& Sims, 1981).

Transverse problems are often overlooked because posterior dental compensation is less apparent than sagittal skeletal discrepancies of the incisors. However, these become apparent during simulated cast surgery. In surgery simulation of a serious skeletal Class II case, by moving the initial casts manually, a bilateral cross-bite occlusion appears, which was not apparent before, because the lower arch has moved to a narrower region of the upper arch. On the contrary, a posterior cross-bite in Class III may not need preoperative management, because it might well be resolved automatically with the posterior surgical mandibular movement, as the lower arch moves to a wider part of the upper arch or as the upper arch moves to a narrower part of the lower arch in cases of surgical maxillary protrusion. Furthermore, in Class III cases with narrow upper arches, the palatal cusps of the molars often interfere with the postoperative position planned, due to insufficient control of the torque. The use of Roth's molar rings with increased torque helps prevent this problem. Thick, rigid, rectangular wire arches are necessary to control torque and maintain the expansion achieved (Winchester \& Young, 2007). The transverse problem needs to be diagnosed from the start. It is also essential to note if it is of dental or skeletal aetiology and if correction is to be achieved through orthodontics, sectional surgery or surgically assisted palatal expansion. Orthodontic expansion should not be attempted preoperatively in patients who are going to undergo surgical expansion. Finally, the only way to check if arch compatibility has been achieved in surgical patients is to mount the study casts on the articulator (Sabri, 2006).

Before the end of the preoperative phase, upper and lower rigid rectangular wires need to be passively in position for eight weeks before surgery. Some type of hooks or brackets with thick attachments should be placed on the wires Kobayashi so as to facilitate immobilisation during surgery. Preoperative orthodontics should have been completed in twelve months and the case needs to be planned in such a way for postoperative treatment, that the final correction may be achieved within six months.

\section{Postoperative orthodontics}

The aim of postoperative orthodontics is to bring the teeth to their final positions and secure balanced occlusion; finally retention planning should be achieved. This phase of the treatment starts two to four weeks later, after a satisfactory range of mandibular movement 
has been achieved and there is good bone healing. At first the occlusal splint is removed as well as the rigid stabilising wires, which are replaced by continuous working wires. This replacement is quite significant, particularly when there are occlusal surfaces only in two or three teeth after the splint is removed, which means that proprioceptive stimuli make the patient try to find a new position with more contact points. This, however, is not desirable because it might complicate the completion of treatment and the healing of recent osteotomies. This problem is avoided if teeth are allowed to freely come to full contact immediately after splint removal. This is better achieved with light, round wires combined with light, box elastics (Sabri, 2006). Postoperative correction of tripod occlusion with a pronounced curve of Spee and lateral open bite usually includes a combination of elastic wire arches with vertical intergnathic elastics and may last slightly longer than usual. When the upper dental arch is flat, a stable upper rectangular arch is maintained, while an elastic arch, for example a braided steel wire, may be placed on the lower arch. When both arches need extrusion, the rectangular arches may be cut and elastics can be applied between the upper and lower sections (Hunt, 2008b). The elastics are not necessarily vertical, but can have an anterior or posterior contributing force to support sagittal correction. For mandibular protrusion Class II elastics should be used (Fig. 13), whereas mandibular retrusion needs Class III elastics. The orthodontist needs to see the patient every two to three weeks at this stage, to continue the controlled guidance towards final occlusion relationships through the elastics and to avoid displacement or deviations of the mandible. Usually patients wear the elastics continously, even when eating, for the first four weeks, continuously but not at meal times for the next four weeks and only at night for another four weeks (Proffit \& Fields, 2007). In cases with a predisposition for open bite, postoperative use of elastics in the buccal sections needs to last the shortest possible time, so as to avoid opening the bite. The use of elastics is terminated after stable occlusion has been achieved. In cases when multiple section osteotomies have been performed and the canine brackets had been preoperatively reversed, it is necessary for them to be reattached, by placing them in the proper position so as to create the right deviation of their longitudinal axes. If palatal expansion was performed intraoperatively, postoperative flexible wires cannot prevent transverse relapse; In order for transverse control to be achieved, a palatal bar can be used (Winchester \& Young, 2007).

The postoperative phase of the treatment needs to be completed within 4-5 months (Slavnic \& Marcusson, 2010) after the operation, because mobilisation and cooperation on the part of patients dwindle after this period (Kiyak et al., 1984).

\section{Retention}

Retention is not different from that of usual orthodontic treatment for adult patients. So, dental movements achieved through preoperative and postoperative orthodontics, need a retention period that follows the removal of fixed appliances. This allows the alveolar bone and periodontal tissues to be reinforced. Where incisors' rotation has been corrected or large spaces closed, a fixed, stable, attached lingual or buccal retention mechanism is used. In other cases, a movable retention appliance may be used (Hunt, 2008b). When surgical or orthodontic expansion has been achieved, it should be maintained with retention for at least 1 year, because it is usually unstable (Phillips et al., 1992). 


\section{References}

Arnett GW, Bergman RT. (1993a). Facial keys to orthodontic diagnosis and treatment planning. Part I. American journal of orthodontics and dentofacial orthopedics, Vol. 103, No. 4, pp. 299-312, ISSN 0889-5406.

Arnett GW, Bergman RT. (1993b). Facial keys to orthodontic diagnosis and treatment planning. Part II. American journal of orthodontics and dentofacial orthopedics, Vol. 103, No. 5, pp. 395-4ll, ISSN 0889-5406.

Athanasiou AE, Kragskov J. (1995). Computerized Cephalometric Systems. In: Orthodontic Cephalometry, Athanasiou AE, pp. 231-239, Mosby-Wolfe, ISBN 072342045 9, London.

Barber AF, Sims MR. (1981). Rapid maxillary expansion and external root resorption in man: a scanning electron microscope study. American Journal of Orthodontics. Vol. 79, No. 6, pp. 630-652, ISSN 0002-9416.

Bass NM. (1991). The aesthetic analysis of the face. European Journal of Orthodontics, Vol. 13, No. 5, pp. 343-50, ISSN 0141-5387.

Baumrind S, Frantz RC. (1971). The reliability of head film measurements. 1. Landmark identification. American journal of orthodontics, Vol. 60, No. 2, pp. 111-127, ISSN $0002-9416$.

Boyd RL. (1978). Mucogingival considerations and their relationship to orthodontics. Journaj of Periodontology, Vol. 49, No 2, pp. 67-76, ISSN 0022-3492.

Burstone CJ. (1967). Lip posture and its significance in treatment planning. American journal of orthodontics, Vol. 53, No. 4, pp. 262-284, ISSN 0002-9416.

Chaconas SJ, Fragiskos FD. (1991). Orthognathic diagnosis and treatment planning: a cephalometric approach. Journal of oral rehabilitation, Vol. 18, No. 6, pp. 531-545, ISSN 0305-182X.

Chaconas SJ, Gonidis D (1986). A cephalometric technique for prosthodontic diagnosis and treatment planning. The Journal of Prosthetic Dentistry, Vol. 56, No. 5, pp. 567-74, ISSN 0022-3913.

Diaz PM, Garcia RG, Gias LN, Aguirre-Jaime A, Pérez JS, de la Plata MM, Navarro EV, Gonzalez FJ.(2010). Journal of Oral and Maxillofacial Surgery. Vol. 68, No. 1, pp. 8892, ISSN 0278-2391.

Eales EA, Newton C, Jones ML, Sugar A. (1994). The accuracy of computerized prediction of the soft tissue profile: a study of 25 patients treated by means of the Le Fort I osteotomy. The International Journal of Adult Orthodontics and Orthognathic Surgery, Vol. 9, No. 2, 141-152, ISSN 0742-1931.

Fish LC, Epker BN. (1980). Surgical-orthodontic cephalometric prediction tracing. Journal of clinical orthodontics, Vol. 14, No. 1, pp. 36-52, ISSN 1079-5154.

Guariglia A, Ronchi P. (2005). Cephalometry in Dentofacial Anomalies, In: OrthodonticSurgical Treatment of Dentofacial Anomalies, Ronchi P, pp. 35-45, Quintessenza, ISBN 88-7492-101-2, Milan Italy.

Harris M, Hunt N. (2008). General Assessment, In: Fundamentals of Orthognathic Surgery, Harris M, Hunt N, pp. 1-22, Imperial College Press, ISBN-13 978-1-86094-993-7, London UK. 
Houston WJB. (1988). Mandibular growth rotations - their mechanisms and importance. European Journal of Orthodontics, Vol. 10, No. 4, pp. 369-373, ISSN 01415387.

Hunt N. (2008a). Radiographic Analysis and Imaging, In: Fundamentals of Orthognathic Surgery, Harris M, Hunt N, pp. 23-39, Imperial College Press, ISBN-13 978-1-86094993-7, London UK.

Hunt N. (2008b). Orthodontic Preparation, In: Fundamentals of Orthognathic Surgery, Harris M, Hunt N, pp. 51-70, Imperial College Press, ISBN-13 978-1-86094-993-7, London UK.

Jacobs JD, Sinclair PM. (1983). Principles of orthodontic mechanics in orthognathic surgery cases. American journal of orthodontics. Vol. 84, No 5, pp. 399-407, ISSN 0002-9416.

Jensen AC, Sinclair PM, Wolford LM. (1992). Soft tissue changes associated with double jaw surgery. American Journal of Orthodontist and Dentofacial Orthopedics, Vol. 101, No. 3, pp. 266-275. ISSN 0889-5406.

Kaipatur NR, Flores-Mir C. (2009). Accuracy of computer programs in predicting orthognathic surgery soft tissue response. Journal of Oral and Maxillofacial Surgery. Vol. 67, No. 4, pp. 751-759. ISSN 0278-2391.

Kapila S, Conley RS, Harrell WE Jr. (2011). The current status of cone beam computed tomography imaging in orthodontics. Dentomaxillofac Radiology, Vol. 40, No. 1, pp. 24-34, . ISSN 0250-832X.

Kiyak HA, Hohl T, West RA, McNeil RW. (1984). Psychologic changes in orthognathic surgery patients: a 24 - month follow up. Journal of Oral and Maxillofacial Surgery, Vol. 42, No. 8, pp. 506-512, ISSN 0278-2391.

Kolokitha OE, Athanasiou AE, Tuncay O. (1996). Validity of computerized predictions of dentoskeletal and soft tissue profile changes after mandibular setback and maxillary impaction osteotomies. The International Journal of Adult Orthodontics and Orthognathic Surgery, Vol. 11, No. 2, pp. 137-154, ISSN 0742-1931.

Kolokitha OE. (2007). Validity of a manual soft tissue profile prediction method following mandibular setback osteotomy. European Journal of Dental, Vol. 1, No. 4, pp. 202-211. ISSN 0141-5387.

Lake SM, McNeill RW, Little RM, West RA. (1981). Surgical mandibular advancement: A cephalometric analysis of treatment response. American journal of orthodontics, Vol. 80, No. 4, pp. 376-394, ISSN 0002-9416.

Langlade M. (1981). Diagnostic orthodontique. Maloine S.A., ISBN 2-224-00738-8, Paris.

Langlade M. (1986). Therapeutique orthodontique. Maloine S.A., ISBN 2-224-00465-6, Paris.

Lee RT. (1994). The benefits of post-surgical orthodontic treatment. British journal of orthodontics. Vol. 21, No 3, pp. 265-74, ISSN:0301-228X.

Levander E, Malmgren O. (1988). Evaluation of the risk of root resorption during orthodontic treatment: a study of upper incisors. European Journal of Orthodontics, Vol. 10, No. 1, pp. 30-38, ISSN 0141-5387.

Lines PA, Lines RR, Lines C. (1978). Profilemetrics and facial esthetics. American journal of orthodontics, Vol. 73, No. 6, pp. 648-657, ISSN 0002-9416. 
Liou EJ, Chen PH, Wang YC, Yu CC, Huang CS, Chen YR. (2011). Surgery-first accelerated orthognathic surgery: postoperative rapid orthodontic tooth movement. Journal of Oral and Maxillofacial Surgery. Vol.69, No.3, pp. 781785, ISSN 0278-2391.

Luther F, Morris DO, Karnezi K. (2007). Orthodontic treatment following orthognathic surgery: how long does it take and why? A retrospective study. Journal of Oral and Maxillofacial Surgery. Vol.65, No.10, pp.1969-1976, ISSN 0278-2391.

McNamara JA. (1984). A method of cephalometric evaluation. American journal of orthodontics, Vol. 86, No. 6, pp. 449-469, ISSN 0002-9416.

McNamara JA, Brudon WL. (1993). Orthodontic and Orthopedic Treatment in the Mixed Dentition, pp. 13-54, Needham Press, ISBN 0-9635022-1-2, Ann Arbor USA.

McNamara JA, Ellis E. (1988). Cephalometric analysis of untreated adults with ideal facial and occlusal relationships. The International journal of adult orthodontics and orthognathic surgery, Vol. 3, No. 4, pp. 221-231, ISSN 0742-1931.

McNeill RW, Proffit WR, White RP. (1972). Cephalometric prediction for orthodontic surgery. The Angle orthodontist, Vol. 42, No. 2, pp. 154-164, ISSN 0003-3219.

Miethke R. (1995). Possibilities and Limitations of Various Cephalometric Variables and Analyses. In: Orthodontic Cephalometry, Athanasiou AE, pp. 63-103, Mosby-Wolfe, ISBN 072342045 9, London.

Muller L. (1962). Cephalometrie et orthodontie, SNPMD, ISBN 2-903482-06-3, Paris.

Onizawa K, Schmelzeisen R, Vogt S. (1995). Alteration of tem $\neg$ poromandibular joint symptoms after orthognathic sur $\neg$ gery: a comparison with healthy volunteers. Journal of oral and maxillofacial surgery, Vol. 53, No. 2, pp. 117-121, ISSN 02782391.

Phillips C, Medland WH, Fields HW, Profitt WR, White RP Jr. (1992). Stability of surgical maxillary expansion. The International Journal of Adult Orthodontics and Orthognathic Surgery, Vol. 7, No. 3, pp. 139-146, ISSN 0742-1931.

Proffit WR. (1991). Treatment planning: The search for wisdom. In: Surgical Orthodontic Treatment. Proffit WR, White RP Jr, pp. 142-191. Mosby, ISBN 0-8016-5291-X, St Louis USA.

Proffit WR, White RP Jr. (1991). Combined Surgical - Orthodontic Treatment: Who Does What, When?. In: Surgical Orthodontic Treatment, Proffit WR, White RP,Jr, pp. 192224, Mosby, ISBN 0-8016-5291-X, St Louis USA.

Proffit WR, Fields HW. (1993). Contemporary Orthodontics Second edition. pp. 607-645, MosbyYear Book, ISBN 0-8016-6393-8, St.Louis USA.

Proffit WR, Sarver DM. (2003). Treatment planning: Optimizing benefit to the patient. In: Contemporary Treatment of Dentofacial Deformity. Proffit WR, White RP,Jr, Sarver DM, pp. 172-244, Mosby, ISBN 0-323-01697-9, St.Louis USA.

Proffit WR, White RP, Jr. (2003). Combining Surgery and Orthodontics: Who Does What, When?. In: Contemporary Treatment of Dentofacial Deformity. Proffit WR, White RP,Jr, Sarver DM, pp. 245-267, Mosby, ISBN 0-323-01697-9, St.Louis USA.

Proffit WR, Fields HW. (2007). Contemporary Orthodontics Fourth edition. pp. 686-718, Mosby, ISBN 13: 978-0-323-04046-4, St.Louis USA. 
Reyneke JP. (2003). Essentials of Orthognathic Surgery, Quintessence Publishing Co, ISBN 086715-410-1, China.

Ricketts RM, Roth RH, Chaconas SJ, Schulhof RJ, Engel GA. (1982). Orthodontic diagnosis and planning Vol 1, pp. 127-147, Rocky Mountain /Orthodontics, LCCN 82-62145, Denver, Colo. U.S.A.

Ricketts RM. (1975). A four-step method to distinguish orthodontic changes from natural growth. Journal of clinical orthodontics, Vol. 9, No. 4, pp. 208-28, ISSN 1079-5154.

Ricketts RM (1981). Perspectives in the clinical application of cephalometrics. The first fifty years. The Angle orthodontist, Vol. 51, No. 2, pp. 115-50, ISSN 0003-3219.

Sabri R. (2006). Orthodontic Objectives in Orthognathic surgery: state of the art today. World Journal of Orthodontics, Vol. 7, No. 2, pp. 177-191, ISSN 1530-5678.

Sassouni V (1958). Diagnosis and treatment planning via roentgenographic cephalometry. American Journal of Orthodontist, Vol. 44, No. 6, pp. 433-463, ISSN 0002-9416.

Sassouni V. (1971). Orthodontics in dental practise, Mosby, ISBN 8016-4300-7, St Louis USA.

Sinclair PM, Proffit WR. (1991). Class III Problems: Mandibular Excess - Maxillary Deficiency. In: Surgical Orthodontic Treatment, Proffit WR, White RP, pp. 428-482. Mosby, ISBN 0-8016-5291-X, St Louis USA.

Slavnic S, Marcusson A. (2010). Duration of orthodontic treatment in conjunction with orthognathic surgery. Swedish Dental Journal, Vol. 34, No. 3, pp. 159-166, ISSN 03479994.

Stroud LP. (1997). Mounted Study Casts and Cephalometric Analysis. In: Science and Practice of Occlusion, McNeill C, pp. 331-348, Quintessence Publishing Co, ISBN 9780867153040. Chicago USA.

Tompach PC, Wheeler JJ, Fridrich KL. (1995).Orthodontic considerations in orthognathic surgery. The International Journal of Adult Orthodontics and Orthognathic Surgery.Vol.10, No2, pp.97-107, ISSN 0742-1931.

Vion P. (1976). Anatomie teleradiographique en norma lateralis. Revue d'Orthopédie DentoFaciale, Vol. 10, No. 4, pp. 449-537, ISSN 0337-9736.

Winchester LJ, Young DR. (2007). Orthodontic Role in Planning: Clinical Aspects, In: Maxillofacial Surgery, Booth PW, Schendel SA, Hausamen J-E, pp. 1211-1223, Churchill Livingstone Elsevier, ISBN-13 978-0-443-10053-6, St. Louis USA.

Wolford LM, Hilliard FW, Dugan DJ. (1985). Surgical Treatment Objective. A Systematic Approach to the Prediction Tracing, Mosby Year Book, ISBN 9780801656095, St Louis USA.

Wolford LM, Stevao ELL, Alexander CM, Goncalves JR. (2004). Orthodontics for Orthognathic Surgery, In: Peterson's Principals of Oral and Maxillofacial Surgery, Miloro M, Ghali GE, Larsen PE, Waite P, pp. 1111-1134, BC Decker Inc, ISBN 1-55009-234-0, Canada.

Wolford LM. (2007). Surgical Planning in Orthognathic Surgery, In: Maxillofacial Surgery, Booth PW, Schendel SA, Hausamen J-E, pp. 1155-1210, Churchill Livingstone Elsevier, ISBN-13 978-0-443-10053-6, St. Louis USA. 
Worms FW, Isaacson RJ, Speidel TM. (1976). Surgical orthodontic treatment planning: prolile analysis and mandibular surgery. The Angle orthodontist, Vol. 46, No. 1, pp. 1-25, ISSN 0003-3219. 


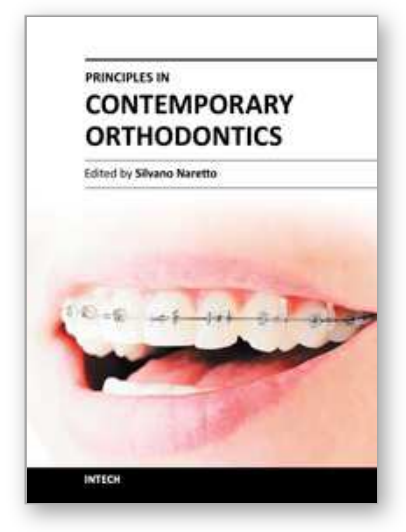

\author{
Principles in Contemporary Orthodontics \\ Edited by Dr. Silvano Naretto
}

ISBN 978-953-307-687-4

Hard cover, 584 pages

Publisher InTech

Published online 25, November, 2011

Published in print edition November, 2011

Orthodontics is a fast developing science as well as the field of medicine in general. The attempt of this book is to propose new possibilities and new ways of thinking about Orthodontics beside the ones presented in established and outstanding publications available elsewhere. Some of the presented chapters transmit basic information, other clinical experiences and further offer even a window to the future. In the hands of the reader this book could provide an useful tool for the exploration of the application of information, knowledge and belief to some orthodontic topics and questions.

\title{
How to reference
}

In order to correctly reference this scholarly work, feel free to copy and paste the following:

Nikolaos Topouzelis (2011). Orthodontic Contribution to Orthognathic Surgery Cases, Principles in Contemporary Orthodontics, Dr. Silvano Naretto (Ed.), ISBN: 978-953-307-687-4, InTech, Available from: http://www.intechopen.com/books/principles-in-contemporary-orthodontics/orthodontic-contribution-toorthognathic-surgery-cases

\section{INTECH}

open science | open minds

\section{InTech Europe}

University Campus STeP Ri

Slavka Krautzeka 83/A

51000 Rijeka, Croatia

Phone: +385 (51) 770447

Fax: +385 (51) 686166

www.intechopen.com

\section{InTech China}

Unit 405, Office Block, Hotel Equatorial Shanghai

No.65, Yan An Road (West), Shanghai, 200040, China

中国上海市延安西路65号上海国际贵都大饭店办公楼405单元

Phone: +86-21-62489820

Fax: +86-21-62489821 
(C) 2011 The Author(s). Licensee IntechOpen. This is an open access article distributed under the terms of the Creative Commons Attribution 3.0 License, which permits unrestricted use, distribution, and reproduction in any medium, provided the original work is properly cited. 